\title{
Análise do escoamento da soja no estado de Mato Grosso do Sul: Perspectiva do corredor bioceânico
}

\author{
Analysis of soybean flow in the state of Mato Grosso do Sul: Perspective of the bioceanic corridor \\ Análisis del flujo de soja en el estado de Mato Grosso do Sul: Perspectiva del corredor bioceánico
}

Recebido: 10/14/2021 | Revisado: 16/12/2021 | Aceito: 17/12/2021 | Publicado: 18/12/2021

Fransérgio Sampatti Santos Matos

ORCID: https://orcid.org/0000-0002-8900-3675 Universidade Federal da Grande Dourados, Brasil Centro Universitário da Grande Dourados, Brasil E-mail: fransergio.matos@unigran.br

João Gilberto Mendes dos Reis

ORCID: https://orcid.org/0000-0001-6409-2299

Universidade Federal da Grande Dourados, Brasil Universidade Paulista, Brasil

E-mail: joao.reis@docente.unip.br

Carla Eloize Carducci

ORCID: https://orcid.org/0000-0001-5736-3775

Universidade Federal da Grande Dourados, Brasi E-mail: carlacarducci@ufgd.edu.br

Alexandre Formigoni

ORCID: https://orcid.org/ 0000-0001-7487-0541 Centro Estadual de Educação Tecnológica Paula Souza, Brasil E-mail: a formigoni@yahoo.com.br

\begin{abstract}
Resumo
Os produtores de soja do estado de Mato Grosso do Sul (MS) enfrentam de forma direta ou indireta o alto custo de transporte para o escoamento do grão através da utilização do modal rodoviário. Desse modo, é preciso encontrar alternativas para aumentar a eficiência desse escoamento aumentando assim a lucratividade dos produtores. Este estudo avalia a utilização do corredor bioceânico Mercosul-Chile em comparação as principais rotas de escoamento da soja do MS para o mercado asiático - principal mercado importador. Para isso adotou-se a metodologia de multicritério Analytic Hierarchy Process (AHP) que visa avaliar alternativas baseadas em critérios e subcritérios. Os dados primários foram coletados via aplicação de questionários aos profissionais da área: comercialização, logística e consultores agrícolas. Por meio deste determinou-se os seguintes critérios: infraestrutura, custo, impacto ambiental e tempo; já os dados secundários foram adquiridos em diversas bases de dados científica: Scopus, Science Direct para assim mensurar os pesos dos critérios e subcritérios: rodovias, portos, frete marítimo, frete rodoviário, pedágios, tarifa portuária, emissão de $\mathrm{CO}_{2}$, consumo de combustível, tempo de viagem, distância rodoviária e distância marítima. Os resultados indicaram que a melhor rota de escoamento da produção de soja no Mato Grosso do Sul para o mercado asiático continua sendo pelo porto de Santos sugerindo assim, a necessidade de novos estudos estratégicos para a utilização do corredor bioceânico no Estado.
\end{abstract}

Palavras-chave: Corredor bioceânico; Escoamento de soja; Exportação.

\begin{abstract}
The soybean producers in the state of Mato Grosso do Sul (MS) face directly or indirectly the high cost of transport for the flow of the grain by road. Therefore, it is necessary to find alternatives to increase the efficiency of this flow, thus increasing the profitability of producers. This study evaluates the use of the Mercosur-Chile bioceanic corridor in comparison with the main routes for soybean distribution from MS to the Asian market - the main importing market. To this end, the multi-criteria Analytic Hierarchy Process (AHP) methodology was adopted, which aims to evaluate alternatives based on criteria and sub-criteria. The primary data was collected via questionnaires applied to professionals in the area: commercialization, logistics, and agricultural consultants. Through this, the following criteria were determined: infrastructure, cost, environmental impact and time; secondary data were acquired in several scientific databases: Scopus, Science Direct to measure the weights of the criteria and sub-criteria: roads, ports, sea freight, road freight, tolls, port tariffs, $\mathrm{CO} 2$ emission, fuel consumption, travel time, road distance and sea distance. The results indicated that the best route for the flow of soy production in Mato Grosso do Sul to the Asian market continues to be through the port of Santos, thus suggesting the need for new strategic studies for the use of the bioceanic corridor in the state.
\end{abstract}

Keywords: Bi-oceanic corridor; Soybean outflow; Export. 


\begin{abstract}
Resumen
Los productores de soja en el estado de Mato Grosso do Sul (MS) enfrentan directa o indirectamente el alto costo del transporte para el flujo del grano a través del uso de la modalidad vial. Por lo tanto, es necesario encontrar alternativas para aumentar la eficiencia de este flujo, aumentando así la rentabilidad de los productores. Este estudio evalúa el uso del corredor bioceánico Mercosur-Chile en comparación con las principales rutas de la soja que fluye desde la EM hacia el mercado asiático, el principal mercado importador. Para ello, se adoptó la metodología del Proceso Analítico Jerárquico (AHP) multicriterio, cuyo objetivo es evaluar las alternativas en función de criterios y subcriterios. Así, los datos primarios se recogieron mediante cuestionarios aplicados a los profesionales del área: consultores de marketing, logística y agricultura. Se determinaron los siguientes criterios: infraestructura, coste, impacto medioambiental y tiempo; se adquirieron datos secundarios en varias bases de datos científicas: Scopus, Science Direct para medir los pesos de los criterios y subcriterios: carreteras, puertos, transporte marítimo, transporte por carretera, peajes, tarifas portuarias, emisión de CO2, consumo de combustible, tiempo de viaje, distancia por carretera y distancia por mar. Los resultados indicaron que la mejor ruta para el flujo de la producción de soja en Mato Grosso do Sul hacia el mercado asiático sigue siendo el puerto de Santos, lo que sugiere la necesidad de nuevos estudios estratégicos para el uso del corredor bioceánico en el estado.
\end{abstract}

Palabras clave: Corredor bioceánico; Flujo de soja; Exportaciones.

\title{
1. Introdução
}

Apesar de ser o maior produtor e exportar mundial de soja (United States Department Agriculture [USDA], 2020), o Brasil, enfrenta diversos desafios para o escoamento do produto. Com uma malha rodoferroviária ineficiente associada ao escoamento limitado a um número pequeno de portos e, estes ainda distantes dos polos de produção, torna a logística de transporte um limitador ao escoamento rápido dos grãos além de refletir negativamente na lucratividade dos produtores. Nota-se que no país há o predomínio do modal rodoviário, deficiente e com infraestrutura inadequada, o que no alto custo de transporte e na ineficiência dos serviços prestados (Biaggioni \& Bovolenta, 2010).

Para o Brasil escoar a safra de grãos os custos de transporte chegam a ser até sete vezes maiores dos custos preconizados nos Estados Unidos. O país além de deter um alto custo de transporte ainda enfrenta dificuldades relacionadas a conservação das rodovias que é considerada de má qualidade, além disso há ainda tem a superlotação dos silos armazenadores nos portos do país. Esse conjunto de fatores influenciam negativamente o escoamento das safras com consequências negativas na capacidade produtiva do agronegócio (Munoz \& Palmeira, 2006).

A manutenção do agronegócio no Brasil deve ser realizada principalmente em infraestrutura logística como relatado por (Jank et al., 2005), pois as estradas são entraves para a produção de grãos, segundo esses autores, sendo que os fatores de baixa eficiência, menor nível de segurança e custo elevados impactam negativamente na competitividade desta importante cadeia de produção.

Neste sentido, algumas alternativas têm sido propostas com a finalidade de tornar esse escoamento mais eficiente. Uma alternativa que vem sendo estudada é o projeto do corredor bioceânico eixo MERCOSUL-Chile que consiste em uma rota rodoviária que ligará os oceanos Atlântico e Pacíficos através de quatros países: Brasil, Paraguai, Argentina e Chile (Asato et al., 2019).

O corredor bioceânico se apresenta como uma boa alternativa para o escoamento da soja do Centro-Oeste, principalmente do estado de Mato Grosso do Sul que não possuí a mesma infraestrutura dos estados vizinhos como Mato Grosso e Goiás. Mato Grosso do Sul, tem perdido competitividade no mercado externo devido a gargalos logísticos, como à falta de infraestrutura rodoviária, políticas públicas eficazes, alta carga tributária, proporcionando assim, o alto custo no escoamento de uma das principais atividades desenvolvidas no agronegócio sul-mato-grossense, a soja (Torres et al., 2017).

De acordo com a Secretaria de Estado Meio Ambiente, Desenvolvimento Econômico, Produção e Agricultura Familiar [SEMAGRO] (2020) o estado do Mato Grosso do Sul apresentou valores expressivos em área plantada no país na safra soja 2018/2019 (10,30\%), ou seja, foram cultivados 280 mil hectares a mais, chegando a 3 milhões de hectares cultivados com essa 
commodity, inserindo assim, o estado entre os cinco maiores produtores de soja do Brasil. Portanto, o corredor bioceânico servirá como uma importante rota para o escoamento da produção da soja para Estado que tem como principal mercado a Ásia (Asato et al., 2019).

Entretanto, faltam estudos que comprovem essa teoria que tem sido apresentada em projeto. É preciso considerar que se realmente haverá a redução dos custos de frete, uma vez que esse custo é mediado pelas cargas de retorno dos portos. Além disso, qual seria a qualidade da infraestrutura dessas rotas e os respectivos custos de pedágio? Por se tratar de uma rota internacional precisaria ainda definir como os respectivos impostos e taxas de exportação seria aplicado.

Diante deste cenário, este artigo visa compreender e preencher essa lacuna e tem como objetivo investigar as principais rotas utilizadas para o escoamento da produção de soja no estado de Mato Grosso do Sul ao mercado asiático comparando-as sob a perspectiva do corredor bioceânico.

Para o alcance dos objetivos, realizou-se uma revisão bibliográficas e documental utilizando dados secundários sobre temas relacionados e dados primários através da aplicação de formulários a dez profissionais atuantes na comercialização, logística e consultores agrícolas na produção de soja. Os dados coletados foram analisados utilizando-se o método de decisão multicritérios, no qual foi escolhido a Analytic Hierarchy Process (AHP), desenvolvido por Saaty (1977). Esta metodologia permitiu que se analisasse diversos pontos que envolve o transporte e exportação da soja, comparando esses fatores de modo conjunto, permitindo um estudo holístico da questão.

\section{Revisão da Literatura}

\subsection{Cadeia da Soja no Mato Grosso do Sul}

Nas últimas décadas é evidente o aumento de produtos denominados flex crops (culturas flexíveis), que apresentam múltiplos usos (alimentação humana, ração animal, combustível e usos industriais). A soja é a matéria-prima que melhor representa esta categoria de produto agrícola, ligada a volatilidade dos preços no mercado mundial (Faccin \& Castillo, 2019).

A soja em Mato Grosso do Sul (MS) deve ter uma variação positiva de 2,7\% em área cultivada passando de 3.360 mil hectares na safra 20/21 para 3450,7 mil hectares na safra 21/22. A projeção da safra 21/22 também aponta um aumento de $2,1 \%$ na produção comparado a safra anterior passando de 12.196,8 mil toneladas para 12.457 mil toneladas (Companhia Nacional de Abastecimento [CONAB], 2021).

O estado de Mato Grosso do Sul é o quinto maior produtor de soja no país, sendo um dos estados que detém maior índice de produtividade. Esse índice apresenta um aumento contínuo nas últimas cincos safras, com uma variação positiva de mais de 20\% comparando a safra 2015/2016 com a safra de 2019/2020 (CONAB, 2021).

As exportações de soja do Estado têm como principal destino a China que representou mais de 1,3 bilhões de dólares no ano de 2020. As principais rotas para escoamento da produção são pelo estado do Paraná e São Paulo através do modal rodoviário chegando até os portos de Paranaguá, São Francisco do Sul e Santos, respectivamente (BRASIL, 2021).

Desse modo, nota-se que o escoamento desta importante commodity acaba tendo como principal meio de transporte o modal rodoviário até os principais portos e chegando até os países importadores através do modal marítimo. A dependência pelo modal rodoviário é evidente e necessária para a cadeia da soja no estado de Mato Grosso do Sul, sendo que este modal acaba sendo a única alternativa de escoamento da produção até os principais portos (Oliveira Junior et al., 2018).

Portanto, para que o Centro-oeste e, consequentemente o estado de Mato Grosso do Sul ganhem competitividade na produção agrícola, são necessários investimentos em infraestrutura, entre outras a restituição em manutenção da malha rodoviária principal meio de transporte do escoamento de grãos (Correa \& Ramos, 2010). 


\subsection{Corredor Bioceânico}

O corredor bioceânico eixo MERCOSUL-Chile tem como objetivo interligar o oceano Atlântico com o Pacífico visando a integração do continente sul-americano entre os seguintes países: Brasil, Paraguai, Argentina e Chile. Todo o percurso do corredor será realizado através do modal rodoviário, com a distância média de 3.200 quilômetros (Asato et al., 2019).

O projeto do corredor surgiu em 2020 com a cúpula de presidentes da América do Sul sendo denominada Iniciativa de Integração da Infraestrutura Regional da América do Sul IIRSA, que tinha como objetivo a buscar a criação de um corredor ou uma rota de integração para o escoamento da produção desses país pelo oceano Pacífico (Fernandes, 2012).

Estima-se uma redução de frete de até $12 \%$ na exportação para o estado de Mato Grosso do Sul de acordo com o Sindicato de Transporte e Logística de MS (SETLOG/MS), esta redução contribuirá para a redução dos custos de produção no agronegócio, principalmente da soja, esta que é uma das principais produções no MS, a redução será essencial para obtenção de competitividade nesta atividade (Asato et al., 2019).

Outro aspecto importante do corredor é o viés turístico, principalmente pela diversidade de atrações turística mescladas pelos quatros países, compostos pelo Pantanal Sul-mato-grossense, o Chaco no Paraguai, as cordilheiras dos Andes na Argentina e por fim as águas do Pacífico no Chile (Castro, 2019).

O extremo sudoeste do estado de Mato Grosso do Sul que faz fronteira com o Paraguai especificamente a cidade de Porto Murtinho saiu do fim de linha para o centro de uma rota, após a finalização da construção da potente que ligara Brasil ao Paraguai a cidade será um dos principais entreposto comerciais do estado (Miranda et al., 2019).

Com a criação do corredor bioceânico, a dinâmica do escoamento da produção, as exportações e o turismo podem se transformar, potencializando o estado de Mato Grosso do Sul e o Brasil, para que o projeto seja desenvolvido são necessárias ações de iniciativa privada e de órgãos públicos para maximizar a possibilidade de resultados positivos (Constantino et al., 2019)

\subsection{Método de Decisão Multicritério do Analytic Hierarchy Process (AHP)}

O método de análise hierárquica do processo (AHP) foi desenvolvido na década de 1970 pelo professor Thomas Lorie Saaty. Tem como objetivo dividir o problema de decisão nos mais variados níveis hierárquicos, onde no nível mais alto concentra-se o problema geral a ser resolvido, nos níveis intermediários ficam os fatores que influenciam na tomada de decisão e no nível mais baixo ficam as alternativas ao problema decisório (Oliveira Neto et al., 2015).

De acordo com Alves e Alves (2015) o AHP como um método de decisão com múltiplos critérios ou objetivos possui grande abrangência de áreas de aplicação, tendo relatos de utilização na educação, medicina, agrícola, pública, indústria e engenharia. Este método busca demonstrar a melhor orientação de tomada de decisão baseada na paridade para os múltiplos critérios definidos, ainda pode avaliar dados quantitativos e qualitativos com graus de certeza e incerteza.

Com a definição da estrutura do problema com a elaboração do objetivo, critérios, subcritérios e alternativas, inicia-se a fase seguinte do método, onde se faz as comparações entre os critérios definidos, através das matrizes de comparação ou de julgamento, onde é criada uma matriz de avaliação $n \times n$, onde n é o número de alternativas, com os valores de comparação $r \_i j$, onde se compara a alternativa ${ }_{i} \operatorname{com}_{j}$ a (Oliveira Neto et al., 2015)

O método AHP converte os critérios em valores, para que o uso de graus possa ser comparado e processado, desta forma elementos imensuráveis podem ser comparados, auxiliando a tomada de decisão para obtenção do objetivo principal. Saaty desenvolveu uma escala absoluta para fazer as comparações entre critérios, onde o primeiro é comparado com o segundo critério, determinando assim, o quanto o primeiro é mais ou menos importante que o segundo (Oliveira Neto et al., 2015)

Para (Oliveira Neto et al., 2015) usa-se uma escala de 1 a 9 de acordo com o Quadro 1, é estabelecido para cada significado um dos índices ímpares e para situações intermediárias utiliza-se valores pares 2 a 8 . 
Quadro 1 - Representação numérica das comparações.

\begin{tabular}{|l|c|l|}
\hline \multicolumn{2}{|c|}{ GRAU } & \multicolumn{2}{c|}{ DESCRIÇÃO } \\
\hline Igual importância & 1 & As duas contribuem igualmente para o objetivo \\
\hline Moderadamente mais importante & 3 & $\begin{array}{l}\text { Importância pequena de uma sobre a outra - A experiência e o } \\
\text { julgamento favorecem fortemente uma atividade em relação à outra. }\end{array}$ \\
\hline Fortemente mais importante & 5 & $\begin{array}{l}\text { Importância grande ou essencial - A experiência e o julgamento } \\
\text { favorecem fortemente uma atividade de relação à outra. }\end{array}$ \\
\hline Muito fortemente mais importante & 7 & $\begin{array}{l}\text { Importância muito grande ou demonstrada - Uma atividade é muito } \\
\text { fortemente favorecida em relação à outra, sua dominação de } \\
\text { importância é demonstrada na prática. }\end{array}$ \\
\hline Extremamente mais importante & 9 & $\begin{array}{l}\text { Importância absoluta - A evidência favorece uma atividade em relação } \\
\text { à outra com mais alto grau de certeza. }\end{array}$ \\
\hline
\end{tabular}

Fonte: Oliveira Neto et al. (2015)

A metodologia AHP utiliza a comparação paritária entre cada um dos critérios, subcritérios, alternativas e a correlação entre os níveis utilizando uma escala nominal, conforme a equação (1), as comparações têm o objetivo determinar os níveis de importância de cada critério e atributo comprando um elemento ${ }_{i}$ a um elemento $_{j}$ (Reis et al., 2016)

$$
A=\left[\begin{array}{cccc}
1 & a_{12} & \ldots & a_{1 n} \\
1 / a_{21} & 1 & \ldots & a_{2 n} \\
\vdots & \vdots & \ldots & \vdots \\
1 / a_{n 1} & 1 / a_{n 2} & \ldots & 1
\end{array}\right]
$$

Onde:

a_ij $>0 \rightarrow$ positiva;

$\mathrm{a} \_\mathrm{ij}=1 \therefore \mathrm{a} \_\mathrm{ij}=1$;

a_ij=1/a_ji $\rightarrow$ recíproca;

a_ij $=$ a_ij.a_jk $\rightarrow$ consistência

Assim, o método AHP correlaciona os diversos critérios e determina a comparação paritária, identificando ainda inconsistências nas análises. Com o lançamento de dados no sistema, se o operador especificar que $a>b$ e que $b>c$, então esperase que a>c, caso contrário é apontada uma inconsistência nos cálculos do software (Reis et al., 2016)

O AHP estabelece um índice de inconsistência expresso matematicamente de acordo com a equação (2), sendo que a inconsistência máxima admitida para garantir a confiabilidade na decisão é IC $<0,1$, caso o resultado seja maior é necessário ajustar as comparações antes de prosseguir na análise dos critérios (Reis et al., 2016).

$$
I C=\frac{\lambda m a ́ x-n}{n-1}
$$

Onde:

$\lambda$ máx $=$ auto valor máximo

$\mathrm{n}=$ dimensão da matriz 


\section{Materiais e Métodos}

\subsection{Procedimentos da pesquisa e Árvore de decisão}

O presente estudo foi conduzido utilizando dados secundários da produção de soja no estado de Mato Grosso do Sul e do Brasil, valores de frete rodoviários e marítimos, taxas portuárias, distâncias e informações de infraestrutura. Foram utilizadas referências bibliográficas e documentais que disponibilizaram informações relevantes para determinação dos critérios e subcritérios em bases de dados nacionais como: Ministério do Desenvolvimento, Indústria e Comércio Exterior [MDIC] Brasil (2021), MAPA (2020), SEMAGRO (2020), Confederação Nacional do Transporte [CNT] (2019), Governo de Santa Catarina (2020), Governo de São Paulo (2018), Governo do Paraná (2020) e internacionais como: USDA (2020), Puerto de Antefogasta (2021) e Puerto de Iquique (2021).

Ainda foram utilizados dados primários, através de questionários aplicados a dez profissionais atuantes na comercialização, logística e consultores agrícolas na produção de soja no estado de Mato Grosso do Sul, sendo que estes ponderavam os critérios (infraestrutura, custo, impacto ambiental e tempo) e ainda foi mensurado a importância para o escoamento da produção de soja no estado de Mato Grosso do Sul para o porto de Shanghai em uma escala de 1 a 9.

As ponderações iniciais nos critérios foram feitas por uma amostra de cinco profissionais de logística, comercialização e especialistas na produção de soja no estado de Mato Grosso do Sul. A árvore de decisão (Figura 1) determina o objetivo, critérios e respectivos subcritérios e por fim aponta as alternativas. Após a construção e identificação das variáveis os dados foram incluídos no SuperDecisions versão 3.2.

Figura 1 - Árvore de decisão para definir a estratégia de escoamento da produção de soja.

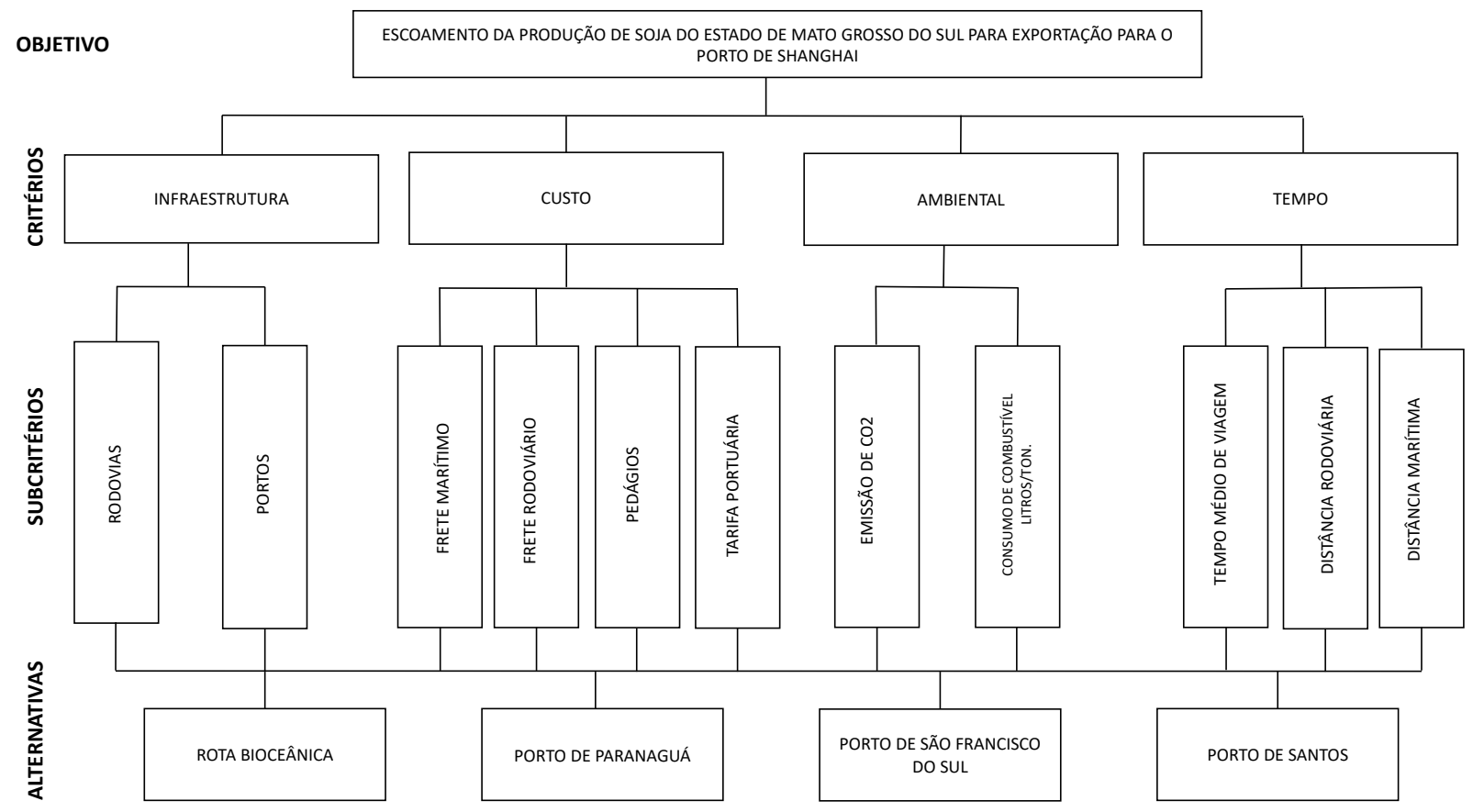

Fonte: Autores.

Após a análise dos critérios com a coleta de dados dos formulários respondido pelos profissionais atuantes em comercialização, logística e produção. Para os subcritérios foram analisados através de dados levantados em plataforma como:

- Tarifas portuárias através da análise nas tabelas tarifárias dos portos de Santos, Paranaguá, São Francisco do Sul, 
Iquique e Antofagasta.

- Distância e frete marítimos na Soybean Transportation Guide BRAZIL 2020 (USDA).

- Escolha das alternativas (Porto de Santos, Paranaguá e São Francisco do Sul), análise de dados da quantidade exportada de soja ao mercado asiático através dos dados do sistema COMEXSTAT/MDIC Brasil (2021).

- Frete e distâncias rodoviárias através do sistema de informação de fretes SIFRECA/ESALQ-LOG (2021).

- Portos através da Agência Nacional de Transporte Aquaviários [ANTAQ] (2020)

- Pedágios através da Agência Nacional de Transporte Terrestre [ANTT] (2020) e Peajes Tarifas 2021/Diccion General de Concesiones.

- Tempo médio de viagem através de variáveis de infraestrutura, distância e pedágios em bases descritas nos respectivos tópicos.

- A emissão de $\mathrm{CO} 2$ e consumo de combustíveis foram analisados através de dados de distancias rodoviárias e marítimas.

O tratamento dos dados foi feito através da análise utilizando o modelo de decisão Analytic Hierarchy Process (AHP) desenvolvido por Saaty (1977), foi conduzida utilizando dados coletados junto as bases nacionais e internacionais e ainda com dados coletados através dos questionários acima discriminados. Para determinar a árvore de dependência e analisar os pesos das comparações paritárias utilizou o software SuperDecisions versão 3.2.

\subsection{Definição do problema}

O problema deste estudo consiste em identificar as melhores rotas para o escoamento da produção de soja do estado de Mato Grosso do Sul para exportação até o porto de Shanghai na China.

Os critérios que vislumbram a tomada de decisão são: Infraestrutura: rodovias e portos; Custo: frete marítimos, frete rodoviário, pedágios e tarifa portuária; Impacto Ambiental: emissão de CO2 e consumo de combustível (litros/toneladas); Tempo: tempo médio de viagem, distância rodoviária e distância marítima. As alternativas foram determinadas pelos três principais portos utilizados para escoamento da produção de soja do estado atualmente (Paranaguá, São Francisco e Santos) e a rota bioceânica.

A definição dos critérios e subcritérios foram determinadas pela pesquisa na literatura, levantamento de dados em bases governamentais e privadas referente a produção, distancias e infraestrutura.

\section{Resultados e Discussão}

\subsection{Resultados}

O critério infraestrutura obteve maior pesos $(0,482)$, seguido por custo $(0,247)$, tempo $(0,176)$ e impacto ambiental $(0,093)$ de acordo com a Tabela 1. Entre as alternativas de escoamento da produção de soja para exportação, a rota até o porto de Santos obteve maior peso $(0,476)$, seguidos pelo Porto de Paranaguá (0,288), Porto de São Francisco de Sul e Rota Bioceânica $(0,059)$. 
Tabela 1 - Pesos dos critérios: infraestrutura, custos, impacto ambiental e tempo.

\begin{tabular}{lcll}
\hline \multicolumn{1}{c}{ Critérios } & Peso & \multicolumn{1}{c}{ Alternativas } & Peso \\
\hline Infraestrutura & 0,482 & Porto de Paranaguá & 0,288 \\
Custo & 0,247 & Porto de Santos & 0,476 \\
Impacto Ambiental & 0,093 & Porto de São Francisco do Sul & 0,175 \\
Tempo & 0,176 & Rota Bioceânica & 0,059 \\
\hline
\end{tabular}

Fonte: Autores.

Os portos de Santos e Paranaguá obtiveram os melhores resultados devido sua distância média rodoviária com o estado de Mato Grosso do Sul e as suas respectivas infraestruturas dos portos e rodovias. O corredor bioceânico não obteve valor expressivo devido a sua distância rodoviária ser expressivamente maior em relação aos portos de Santos e Paranaguá, mesmo que a distância marítima seja menor, porém o custo do frete rodoviário é expressamente maior em relação ao frete marítimo.

\subsection{Critérios, subcritérios e alternativas}

Os critérios (infraestrutura, custo, impacto ambiental e tempo) foram avaliados de acordo com as respostas dos questionários, aplicados aos especialistas da área no estado de Mato Grosso do Sul, nesta pesquisa foram formuladas perguntar que mensuraram a importância de um critério em relação ao outro e ainda pontuaram em uma escala de 1 a 9 (Tabela 2 ).

Tabela 2 - Pesos dos critérios, subcritérios e alternativas.

\begin{tabular}{|c|c|c|c|c|c|}
\hline \multirow[b]{2}{*}{ Critérios } & \multirow[b]{2}{*}{ Subcritérios } & \multicolumn{4}{|c|}{ Alternativas } \\
\hline & & $\begin{array}{c}\text { Porto de } \\
\text { Paranaguá }\end{array}$ & $\begin{array}{l}\text { Porto de } \\
\text { Santos }\end{array}$ & $\begin{array}{l}\text { Porto de São } \\
\text { Francisco do } \\
\text { Sul }\end{array}$ & $\begin{array}{c}\text { Rota } \\
\text { Bioceânica }\end{array}$ \\
\hline \multirow{2}{*}{$\begin{array}{l}\text { Infraestrutura } \\
(0,482)\end{array}$} & Rodovias $(0,750)$ & 0,242 & 0,501 & 0,171 & 0,083 \\
\hline & Portos $(0,250)$ & 0,268 & 0,529 & 0,134 & 0,068 \\
\hline \multirow{4}{*}{ Custo $(0,247)$} & Frete Marítimo $(0,274)$ & 0,115 & 0,199 & 0,078 & 0,606 \\
\hline & Frete Rodoviário $(0,511)$ & 0,327 & 0,461 & 0,166 & 0,044 \\
\hline & Pedágios $(0,153)$ & 0,117 & 0,045 & 0,177 & 0,659 \\
\hline & Tarifas Portuárias $(0,061)$ & 0,217 & 0,113 & 0,627 & 0,041 \\
\hline \multirow{2}{*}{$\begin{array}{l}\text { Impacto } \\
\text { Ambiental } \\
(0,093)\end{array}$} & Emissão de CO2 $(0,250)$ & 0,288 & 0,476 & 0,175 & 0,059 \\
\hline & $\begin{array}{l}\text { Consumo de combustível lit./ton. } \\
(0,750)\end{array}$ & 0,288 & 0,476 & 0,175 & 0,059 \\
\hline \multirow{3}{*}{ Tempo $(0,176)$} & Tempo médio de viagem $(0,649)$ & 0,152 & 0,289 & 0,117 & 0,441 \\
\hline & Distância Rodoviária $(0,071)$ & 0,302 & 0,443 & 0,203 & 0,050 \\
\hline & Distância Marítima $(0,278)$ & 0,126 & 0,261 & 0,089 & 0,523 \\
\hline
\end{tabular}

Fonte: Autores.

Para apurar os pesos dos subcritérios foram utilizados dados secundários para chegar aos resultados descritos na tabela 3 pesquisados em bases como: MDIC Brasil (2021), MAPA (2020), SEMAGRO (2020), CNT (2019), Governo de Santa Catarina (2020), Governo de São Paulo (2018), Governo do Paraná (2020) e intencionais como: USDA (2020), Puerto de Antefogasta (2021), Puerto de Iquique (2021) e Google Maps®. As distâncias rodoviárias foram calculadas com base na capital do estado Campo Grande, a marítima nas rotas porto de Santos, Paranaguá e São Francisco do Sul considerando a rota Cabo da Boa Esperança. Na rota bioceânica foi utilizado o porto de Uquique como base nas tarifas portuárias e o pedágio na sua respectiva 
rota. Os fretes rodoviários e marítimos foram considerados através das respectivas distâncias devidos as constantes variáveis de valores, baseados no câmbio, em tabelas de frete e na disponibilidade.

Tabela 3 - Distâncias, pedágios e tarifas portuárias.

\begin{tabular}{lllll}
\hline \multicolumn{1}{c}{ Rota } & Rodoviária (km) & Marítima (nm) & $\begin{array}{c}\text { Pedágios } \\
\text { (eixo) }\end{array}$ & $\begin{array}{c}\text { Tarifa portuária } \\
\text { (ton.) }\end{array}$ \\
\cline { 2 - 4 } & 1096 & 12170 & $\mathrm{R} \$ 183,90$ & $\mathrm{R} \$ 3,95$ \\
Santos & 1103 & 13165 & $\mathrm{R} \$ 97,70$ & $\mathrm{R} \$ 3,18$ \\
Paranaguá & 1178 & 13226 & $\mathrm{R} \$ 86,40$ & $\mathrm{R} \$ 1,43$ \\
São Francisco do Sul & 2396 & 10085 & $\mathrm{R} \$ 6,42$ & $\mathrm{R} \$ 13,34$ \\
Bioceânica & & & & \\
\hline
\end{tabular}

Fonte: Autores.

\subsubsection{Infraestrutura}

O critério infraestrutura foi o que mais impactou na decisão de escolha de rota para exportação da produção de soja com peso 0,482, sendo que no Brasil o modal predominante no escoamento de soja é o rodoviário, principalmente pela falta de infraestrutura, mesmo com custo elevado em comparação ao ferroviário e hidroviário. Ao comparar o Brasil com Estados Unidos, China e Rússia que são os maiores países territoriais, percebe-se a tendência de investimentos em modais com custos menores devido à distância, porém atualmente isto não acontece no Brasil (Araújo et al., 2018)

O subcritério com maior peso foi o das rodovias $(0,750)$, a má conservação das estradas traz prejuízos importantes para o agronegócio brasileiro, pois grande parte da produção é escoada por rodovias, considerado uns dos custos de transporte mais altos por ser altamente dependente do preço do combustível e dos pedágios (Kussano \& Batalha, 2012).

Os portos tiveram peso 0,250 , sendo que os principais utilizados atualmente no país tornam-se um gargalo na exportação da soja, pela sua baixa capacidade de armazenamento não ser condizente com a produção e exportação atual do país (Araújo et al., 2018)

\subsubsection{Custo}

O critério custo obteve o peso de 0,247, a distância entre os estados da região Centro-oeste e os portos de escoamento da produção para exportação é relevante na determinação do custo de produção da soja. O subcritério frete rodoviário teve maior peso $(0,511)$ por ser realizado através do modal rodoviário e considerado de alto custo, sendo que representa cerca de $10 \%$ do preço do produto, o que denota sua importância (Oliveira et al., 2015).

O frete marítimo obteve peso 0,274 , que tem como vantagem a alta capacidade de transportar imensas quantidades em uma única viagem, com isso, seu custo se torna baixo, tendo com desvantagens problemas relacionados a infraestrutura de portos pois necessita de transbordo e assim enfrenta constantes congestionamento nos portos, seu baixo custo justifica o peso obtido no tópico custos (Silva \& Curi, 2018)

Os pedágios como subcritério de avaliação tiveram peso de 0,153 , de acordo com dados de estudos desenvolvidos pela Secretaria de Transporte do Estado de São Paulo, este corresponde a 8,6\% do valor do frete, sendo que as concessões de rodovias incluem a obrigatoriedade da execução de obras de ampliação e melhorias (Reis et al., 2016). Por fim, o subcritério tarifas portuárias com peso de 0,061 foi considerada um dos fatores portuários que podem prejudicar a competitividade das exportações, devido a sua composição no custo estabelecidos pelas administradoras de portos de acordo com suas características (Dubke, 2006). 


\subsubsection{Impacto Ambiental}

O critério de impacto ambiental obteve o peso de 0,093, e seus subcritérios: Consumo de combustível e Emissão de $\mathrm{CO} 2$, obtiveram os valores de 0,75 e 0,25 respectivamente. $\mathrm{O}$ transporte foi considerado uma das atividades de maior impacto ao meio ambiente, devido o uso de combustível fóssil (gasolina e diesel), padrões sustentáveis para a realização desta importante atividade torna-se imprescindível. Projetos inovadores e alternativos sobre os sistemas de transporte, devem ser priorizados, com vistas a redução do consumo de energia e emissões de poluentes, especialmente pelo peso dessa atividade em conjunto com o agronegócio que representam significativa importância nas discussões atuais em relação a conservação do meio ambiente (Zioni \& Freitas, 2015)

\subsubsection{Tempo}

O tempo obteve o peso de 0,176, considerado um fator que através da sua redução, garante maior agilidade na logística e melhor nível de serviço, gerando assim impacto positivo na competitividade no escoamento da soja (Araújo et al., 2018).

O tempo médio de viagem apresentou uma alta relevância nas decisões da exportação com o peso de 0,649, corroborando com (Reis \& Leal, 2014), que considerou um dos fatores mais importantes na logística de transporte de cargas. A distância marítima $(0,278)$ e distância rodoviária $(0,071)$, como respectivos subcritérios do tempo, esse são determinantes no processo de transporte, sendo que é considerado como um dos agravantes nas restrições para o aumento do volume exportado devido as incertezas inerentes no seu processo (Oliveira et al., 2015).

\section{Considerações Finais}

A infraestrutura é o critério que tem maior peso na decisão de escolha de uma rota de escoamento, seguido pelos critérios custos, impacto ambiental e tempo. Sendo que ainda os subcritérios rodovias, frete rodoviário, consumo de combustíveis e tempo médio de viagem se destacaram com pesos maiores na escolha da rota. Assim, a alternativa que demonstra melhor resultado no escoamento da produção da soja no MS ao mercado asiático é até o Porto de Santos, seguida pelo Porto de Paranaguá, São Francisco do Sul e Rota Bioceânica, as distâncias rodoviárias, as infraestruturas de portos e rodovias, as distâncias marítimas tiveram grande expressão para determinar tal resultado.

A rota bioceânica obteve o menor peso nas alternativas, principalmente pela sua distância rodoviária com o Estado, mesmo que sua distância marítima é menor comparada com as outras alternativas, no entanto, os custos de transporte rodoviário são expressivamente maior comparados aos custos do transporte marítimo, outro ponto relevante no resultado foi a infraestrutura rodoviária e portuária que ainda se mostram frágil para comportar o escoamento deste commodity.

Diante dos resultados, a rota bioceânica mostra-se inviável para o escoamento da produção de soja no estado de Mato Grosso do Sul para o mercado asiático comprada as três principais rotas utilizadas atualmente (Porto de Santos, Paranaguá e São Francisco do Sul) que demonstram-se ser mais eficientes nos quatro critérios determinantes para o escoamento da produção de soja (infraestrutura, custo, ambiental e tempo).

Foi possível inferir que as alternativas representam as melhores rotas de escoamento da produção da soja no MS, direcionadas pelas variáveis que foram usadas como critérios e subcritérios para avaliar a melhor alternativa. Entretanto, o transporte da produção de soja do estado pode ser realizado em outras rotas com surgimento de novos projetos de infraestrutura rodoviária, ferroviária e marítima.

Como trabalhos futuros sugere-se avaliar novas perspectivas diante da utilização do corredor bioceânico, para mensurar sua utilização em cenários futuros que sejam competitivos a exportação da soja brasileira. Além disso, sugere-se o estudo da viabilidade do corredor como alternativa para o transporte de outros produtos agrícolas e de produtos industriais com maior valor agregado. 


\section{Referências}

Antaq (2020). Agência Nacional de Transportes Aquaviários. Brasil. https://www.gov.br/antaq/pt-br/noticias/2021/antaq-apresenta-seu-relatorio-de-gestao2020 .

Antt (2020). Agência Nacional de Transportes Terrestres. Brasil. https://portal.antt.gov.br/documents/860252/862899/Relat\%C3\%B3rio+Anual+202 0.pdf/22a726b9-d204-2f2d-613b-1ad9c42a12dc?t=1591905684473

Alves, J. R. X., \& Alves, J. M. (2014). Definição de localidade para instalação industrial com o apoio do método de análise hierárquica (AHP). Production, 25(1), 13-26. https://doi.org/10.1590/S0103-65132014005000023

Araújo, L., Senne, C. M., \& Lima, J. P. (2018). Estudo de alternativas de escoamento da soja brasileira por meio de um modelo de decisão multicritério. Anais do Encontro Nacional de Engenharia de Produção, Maceió. https://doi.org/10.14488/ENEGEP2018_TN_STP_258_481_36401

Asato, T. A., Gonçalves, D. F., \& Wilke, E. P. (2019). Perspectiva do Corredor Bioceânico para o Desenvolvimento local do estado de MS: o caso de Porto Murtinho, 20, 141-158.

Biaggioni, M. A. M., \& Bovolenta, F. C. (2010). Balanço energético comparativo para rotas de escoamento de soja. Engenharia Agrícola, 30(4), 587-599. https://doi.org/10.1590/S0100-69162010000400003

Brasil. MDIC. Comex Stat, 2021. Portal do Comércio Exterior do Brasil. http://comexstat.mdic.gov.br/pt/home.

Castro, J. C. P. DE. (2019). Turismo como instrumento dinamizador do Corredor Rodoviário Bioceânico. Interações, 20, 19-29. http://dx.doi.org/10.20435/inter.v20iespecial.2419

Companhia Nacional de Abastecimento (2021). Tabela de dados - Produção e balanço de oferta de demanda de grãos. CONAB. https://www.conab.gov.br/infoagro/safras/graos.

Cnt (2019). Confederação Nacional do Transporte. Pesquisa Rodoviária https://pesquisarodovias.cnt.org.br/downloads/ultimaversao/Pesquisa_CNT_Rodovias_2019_Web.pdf.

Correa, V. H. C., \& Ramos, P. (2010). A precariedade do transporte rodoviário brasileiro para o escoamento da produção de soja do Centro-Oeste: Situação e perspectivas. Revista de Economia e Sociologia Rural, 48(2), 447-472. https://doi.org/10.1590/S0103-20032010000200009

Constantino, M., Dorsa, A. C., Boson, D. S., \& Mendes, D. R. F. (2019). Caracterização econômica dos municípios sul-mato-grossenses do Corredor Bioceânico. Interações, 20, 179-192. https://doi.org/10.20435/inter.v20iespecial.2119

Dubke, A. F. (2006). Modelo de localização de terminais especializados: um estudo de caso em corredores de exportação da soja. [Tese de Doutorado em Engenharia Industrial, Pontifícia Universidade Católica do Rio de Janeiro], Repositório BDTD. http://bdtd.ibict.br/vufind/Record/PUC_RIO1_e07eaae352c218604eae2099a729cc48

Faccin, A. C. T. M., \& Castillo, R. (2019). A centralidade do complexo-soja na economia brasileira e a manutenção da produção agrícola extravertida: Análise da soja em Mato Grosso do Sul. Geosul, 34(71), 111-129. https://doi.org/10.5007/1982-5153.2019v34n71p111

Fernandes, R. M. da S. (2012). A Rota Rodoviária Bioceânica como instrumento de interação entre discursos e práticas em uma Zona de Fronteira: Uma rodovia e vários caminhos [Dissertação Mestrado em Geografia, Universidade Federal da Grande Dourados]. Repositório UFGD. https://files.ufgd.edu.br/arquivos/arquivos/78/MESTRADO-DOUTORADO-GEOGRAFIA/Disserta\%C3\%A7\%C3\%A3o(30).pdf

Governo do Paraná (2020). Tabela Tarifária do Porto de Paranaguá. https://www.documentador.pr.gov.br/documentador/pub.do?action=d\&uuid=@gtfescriba-appa@d49157ed-4071-4558-824a-a066c619996e\&emPg=true

Governo de Santa Catarina (2020). Tabela Tarifária do Porto de São https://portosaofrancisco.com.br/public/uploads/pdfs/TARIFASCPARPSFS.pdf

Governo de São Paulo (2018). Tabela Tarifária do Porto de Santos. http://intranet.portodesantos.com.br/docs_codesp/doc_codesp_pdf_site.asp?id=123629

Kussano, M. R., \& Batalha, M. O. (2012). Custos logísticos agroindustriais: Avaliação do escoamento da soja em grão do Mato Grosso para o mercado externo. Gestão \& Produção, 19(3), 619-632. https://doi.org/10.1590/S0104-530X2012000300013

Jank, M. S., Nassar, A. M., \& Tachinardi, M. H. (2005). Agronegócio e comércio exterior brasileiro. Revista USP, O(64), 14. https://doi.org/10.11606/issn.23169036.v0i64p14-27

Mapa (2020). Ministério da Agricultura, Pecuária e Abastecimento. Brasil. https://www.gov.br/agricultura/pt-br/centrais-de-conteudo/biblioteca/agrobase

Miranda, M. G., Friede, R., \& Avelar, K. (2019). Capital social e os desafios do Corredor Bioceânico. Interações, 20, 211-224. https://doi.org/10.20435/inter.v20iespecial.2538

Munoz, C. C., Palmeira, E. M. (2006). Desafios de logística nas exportações brasileiras do complexo agronegocial da soja. Revista Académica de Economia, 71, $1-9$.

Oliveira Junior, E. F. de, Casarotto, E. L., Mendonça, J. C. A., Binotto, E., \& Silva, M. V. A. P. da. (2018). Exportação de soja no estado de Mato Grosso do Sul: características da comercialização. Revista em Agronegócio e Meio Ambiente, 11(1), 71. https://doi.org/10.17765/2176-9168.2018v11n1p71-97

Oliveira Neto, M. S. de, Reis, A. D. C., Stender, G. H. C., Costa, W. O. da, \& Souza, C. G. de. (2015). Avaliação dos critérios de seleção de transportador e modais para o escoamento da safra de soja brasileira. Revista Produção e Desenvolvimento, 1(1), 14-30. https://doi.org/10.32358/rpd.2015.v1.57 
Research, Society and Development, v. 10, n. 16, e534101624605, 2021

(CC BY 4.0) | ISSN 2525-3409 | DOI: http://dx.doi.org/10.33448/rsd-v10i16.24605

Oliveira, R. V., Guedes, I.; Silva, R. H. B. (2015). Análise dos custos logísticos de transporte no escoamento de soja do estado de Mato Grosso do Sul para os portes de Paranaguá e Santos. Multitemas, 47, 57-75.

Peajes Tarifas (2021). Dirección General de Concesiones/Rutas Transversales. Chile. http://www.concesiones.cl/peajesporticos/Documents/2021/Transve rsales/MOP-DGC-Tarifas-2021-Tranvesales-ANTOFAGASTA.pdf

Puerto de Antofagasta (2021). Reglamento de Operaciones. Chile. https://www.anfport.cl/wp-content/uploads/2021/07/2021_Reglamento-OperacionesTMO_Desde-AGO-2021.pdf

Puerto de Iquique (2021). Reglamento de Operaciones. Chile. https://epi.cl/puerto-de-iquique/servicios/tarifas/

Reis, J. G. M., Vendrametto, O., Naas, I. de A., Costabile, L. T., \& Machado, S. T. (2016). Avaliação das Estratégias de Comercialização do Milho em MS Aplicando o Analytic Hierarchy Process (AHP). Revista de Economia e Sociologia Rural, 54(1), 131-146.

Saaty, T. L. (1977). A scaling method for priorities in hierarchical structures. Journal of mathematical psychology, 15(3), 234-281. https://doi.org/10.1590/1234$56781806-9479005401007$

Reis, S. A. and Leal, J. E. (2014) Uso do conceito de hipercaminhos no transporte de carga: uma análise exploratória. Journal of Transport Literature, 8(2), 271294.

Secretaria de Estado de Meio Ambiente, Desenvolvimento Econômico, Produção e Agricultura Familiar (2020). Carta de Conjuntura. SEMAGRO. https://www.semagro.ms.gov.br/carta-conjuntura-setor-externo/

Sifreca - Sistema de Informação de Fretes (2021). ESALQ/USP. https://sifreca.esalq.usp.br/mercado/soja

Silva, R. F.; Curi, M. A. (2018). Custos Logísticos: um estudo sobre a composição do frete rodoviário entre zonas aduaneiras. Brasilian Jornal of Development, 4(7), 3773-3788.

Torres, O., Fagundes, M. B. B., Figueiredo, A. M. R., \& Tredezini, C. A. de O. (2017). Impacto da Implantação do Custo do Pedágio na BR-163 em Relação ao Transporte de Soja do Estado de Mato Grosso. Revista de Economia e Sociologia Rural, 55(3), 533-550. https://doi.org/10.1590/1234-56781806-94790550307

Usda (2020). United States Department of Agriculture. Oilseeds: World Markets and https://www.ams.usda.gov/sites/default/files/media/BrazilSoybeanTransportationGuide2020.pdf

Usda (2021). United States Department of Agriculture. Oilseeds: World Markets and Trade. https://downloads.usda.library.cornell.edu/usdaesmis/files/tx31qh68h/np1949882/r781xh263/oilseeds.pdf.

Zioni, S., \& Freitas, S. R. de. (2015). Aspectos ambientais no Plano Nacional de Logística e Transporte do Brasil. Desenvolvimento e Meio Ambiente, 35, 195208. https://doi.org/10.5380/dma.v35i0.41575 